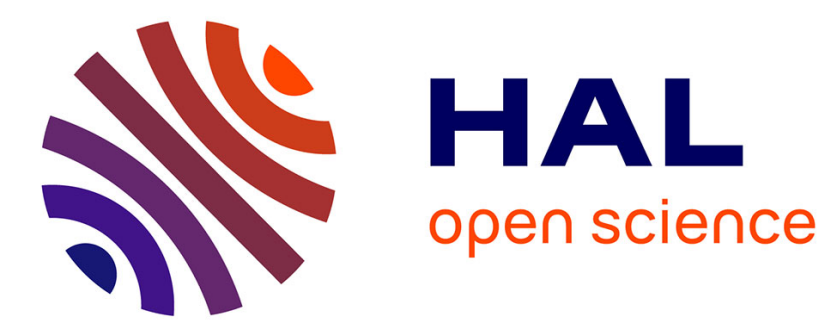

\title{
Stripping experiments in carbon foils with heavy ions in the energy range of 0.4-0.9 mev/a
}

\author{
G. Frick, V. Chaki, B. Heusch, Ch. Ricaud, P. Wagner, E. Baron
}

\section{To cite this version:}

G. Frick, V. Chaki, B. Heusch, Ch. Ricaud, P. Wagner, et al.. Stripping experiments in carbon foils with heavy ions in the energy range of 0.4-0.9 mev/a. Revue de Physique Appliquée, 1977, 12 (10), pp.1525-1533. 10.1051/rphysap:0197700120100152500 . jpa-00244361

\section{HAL Id: jpa-00244361 https://hal.science/jpa-00244361}

Submitted on 1 Jan 1977

HAL is a multi-disciplinary open access archive for the deposit and dissemination of scientific research documents, whether they are published or not. The documents may come from teaching and research institutions in France or abroad, or from public or private research centers.
L'archive ouverte pluridisciplinaire HAL, est destinée au dépôt et à la diffusion de documents scientifiques de niveau recherche, publiés ou non, émanant des établissements d'enseignement et de recherche français ou étrangers, des laboratoires publics ou privés. 


\title{
STRIPPING EXPERIMENTS IN CARBON FOILS WITH HEAVY IONS IN THE ENERGY RANGE OF 0.4-0.9 MEV/A
}

\author{
G. FRICK, V. CHAKI, B. HEUSCH, Ch. RICAUD, P. WAGNER \\ Centre de Recherches Nucléaires, 67037 Strasbourg Cedex, France \\ and E. BARON \\ Institut de Physique Nucléaire, B.P. 1, 91406 Orsay, France
}

\begin{abstract}
Résumé. - Nous avons étudié les propriétés des ions lourds épluchés par des feuilles de carbone. Des ions $\mathrm{Ni}$, I et $\mathrm{Au}$ de 0,4 à $0,9 \mathrm{MeV} / A$ ont été utilisés pour bombarder des feuilles de 5 à $200 \mu \mathrm{g} / \mathrm{cm}^{2}$. Au cours de ces mesures les ions étaient observés à l'aide d'un spectromètre Browne-Buechner.

Nous avons mesuré la dispersion angulaire des ions ainsi que la dispersion en énergie. Nous avons étudié le comportement des feuilles sous l'effet du bombardement par des faisceaux de grande densité de courant (quelques $\mu \mathrm{Ap} / \mathrm{cm}^{2}$ sur une surface de 1-2 $\mathrm{mm}^{2}$ ). Nous avons observé la variation de l'épaisseur des feuilles au cours du bombardement pour une valeur de la pression de quelque $10^{-6}$ et quelque $10^{-7}$ torr. Nous avons regardé l'évolution de la dispersion en énergie durant les expositions et nous concluons que ce paramètre ne change pas de façon importante. Ceci signifie que des phénomènes comme l'épaississement ou le sputtering n'affectent pas l'homogénéité de la feuille. Nous rapportons également des résultats sur la durée de vie des feuilles.
\end{abstract}

\begin{abstract}
We studied the properties of heavy ions stripped by carbon foils. Ni, I and Au ions of 0.4 $-0.9 \mathrm{MeV} / A$ were used to bombard foils of $5-200 \mu \mathrm{g} / \mathrm{cm}^{2}$. In these measurements the ions were detected in a Browne-Buechner spectrometer.

We measured the angular straggling of the ions and the energy straggling. We looked for the behaviour of the foils under impact of large beam densities (several $\mu \mathrm{Ap} / \mathrm{cm}^{2}$ on an area of $1-2 \mathrm{~mm}^{2}$ ). We observed the thickness variations of the foils during bombardment in a vacuum of $\sim 10^{-6}$ and $10^{-7}$ torr. We looked for the evolution of the energy straggling during exposure and conclude that this parameter does not change in an important way. This means that neither thickening nor sputtering affects the homogeneity of the foil. Results on the lifetime of the bombarded foils are reported.
\end{abstract}

The work described in this paper has been done, in connection with the french heavy ion accelerator (Ganil) [1, 2], to find out the properties and the behaviour under which they will be used in this accelerator.

The French heavy ion accelerator consists of two separated sector cyclotrons of strength $K=400$. Heavy ions accelerated by the first cyclotron will be stripped before injection into the second cyclotron which will accelerate the ions to their final energy. The particle energies at the stripper and the charge states required are such that, except for light ions $(A<40)$, a foil will be necessary for the stripper $[3,4,5]$.

Table I gives some characteristic numbers for the beam at this stage. The energy values $E 1$, and the incident intensity $I$ of the ion beams at the stripper necessary to obtain the maximum and minimum required values at the output of the second cyclotron are reported. $E 1$ varies from the minimum value of $0.25 \mathrm{MeV} / A$ (i.e. the energies on the terminal of the new generation of tandems) to the maximum numbers between $0.5 \mathrm{MeV} / A(119 \mathrm{MeV})$ for uranium and $6 \mathrm{MeV} / A(72 \mathrm{MeV})$ for carbon. The energy dispersion should be between $0.4-1 \times 10^{-3}$ at the output of the second stage according to the different cases. In order to obtain the required intensity of $0.1-1 \times 10^{12} \mathrm{pps}$ at the output, the intensity on the stripper should be between 2 and $17 \times 10^{12} \mathrm{pps}$, which corresponds to a particle $\mu$ A range.

Finally the requirements in the emittance lead to numbers at the stripper level between $10 \pi$ and $20 \pi$ $\mathrm{mm} . \mathrm{mrad}$. For instance, for ${ }^{131 \mathrm{Xe}}$ ions, $E=1.6 \mathrm{MeV} / A, I=10^{13}$ pps $(1.6 \mu \mathrm{Ap}), \xi=10 \pi$, the corresponding beam would have a divergence of $2 \mathrm{mrad}$, for a diameter of $1 \mathrm{~cm}$ if it has a circular shape on the carbon foil.

Since the beginning the Ganil Group has been faced with intensity questions. Knowing, that the intensity at the output should have fixed emittance and energy dispersion, any deterioration of the beam quality during acceleration has a consequence on the stripping regime. Especially following questions arise:

1) What is the angular straggling of the ions with energies and masses corresponding to the Ganil project? There existed measurements for lighter ions at 
TABLE I

$q$, charge state of the ion source. $E_{1}$, ion energy after the first cyclotron. $\bar{q}_{\mathrm{s}}$, average charge state of the ions after stripping. $q_{\mathrm{s}}$, charge state selected for injection into the second cyclotron. $\eta_{\mathrm{s}}$, stripping probability for the charge state $q_{\mathrm{s}}$. I incident, beam intensity on the stripper. $E_{2}$ and I, energy and maximum required intensity of the ions after the second cyclotron.

\begin{tabular}{|c|c|c|c|c|c|c|c|c|}
\hline & $q$ & $E_{1}$ & & & & acident & & $I$ \\
\hline & source & $\mathrm{MeV} / A$ & $\bar{q}_{\mathrm{s}}$ & $q_{\mathrm{s}}$ & $\eta_{\mathrm{s}}$ & $\times 10^{12} \mathrm{pps}$ & $\mathrm{MeV} / A$ & $\times 10^{12} \mathrm{pps}$ \\
\hline $\mathrm{C}$ & 2 & 6 & 5 & 6 & 0.5 & 5.7 & 95 & 1 \\
\hline $\mathrm{Ar}$ & 5 & 4.7 & 18 & 18 & 0.32 & 8.2 & 75 & 1 \\
\hline $\mathrm{Kr}$ & 8 & 2.8 & 28 & 30 & 0.10 & 17.1 & 45 & 0.6 \\
\hline $\mathrm{Xe}$ & 9 & 1.6 & 34 & 36 & 0.10 & 11.4 & 25 & 0.4 \\
\hline $\mathrm{Au}$ & 9 & 0.8 & 36 & 38 & 0.12 & 5.7 & 12 & 0.2 \\
\hline $\mathrm{U}$ & 9 & 0.5 & 26 & 32 & 0.06 & 4.8 & 8 & 0.1 \\
\hline C & 1 & 0.25 & 4 & 4 & 0.50 & 5.7 & 4 & 1 \\
\hline $\mathrm{Ar}$ & 2 & 0.25 & 8 & 8 & 0.32 & 8.2 & 4 & 1 \\
\hline $\mathrm{Kr}$ & 3 & 0.25 & 12 & 12 & 0.23 & 7.4 & 4 & 0.6 \\
\hline $\mathrm{Xe}$ & 4 & 0.25 & 17 & 16 & 0.14 & 8.2 & 4 & 0.4 \\
\hline $\mathrm{Au}$ & 5 & 0.25 & 21 & 20 & 0.16 & 3.6 & 4 & 0.2 \\
\hline $\mathrm{U}$ & 6 & 0.25 & 22 & 24 & 0.13 & 2.2 & 4 & 0.1 \\
\hline
\end{tabular}

smaller energies where theories have been developed. Do these theoretical predictions apply to the situation of Ganil?

2) What is the energy straggling keeping in mind the same remarks as for 1 .

3) What are the lifetimes of the stripping foils or more exactly how do they evoluate with time?

4) Is there a relation between equilibrium - thickness and lifetimes as has been proposed?

1. Experimental methods. - Particles of the requisite energies were obtained from the Van de Graaff MP tandem accelerator of Strasbourg with energies between $0.5-1 \mathrm{MeV} / A$ on carbon foils having a thickness in the range $5-200 \mu \mathrm{g} / \mathrm{cm}^{2}$. Ions $\mathrm{Ni}$, I and $\mathrm{Au}$ have been chosen. Ni because it has a mass comparable with others already studied I, which is an intermediate mass ion and Au because it is the heaviest projectile that can be easily obtained.

The straggling and equilibrium thickness experiments (Fig. 1) needed only small intensities but we demanded a high beam quality. So, with help of

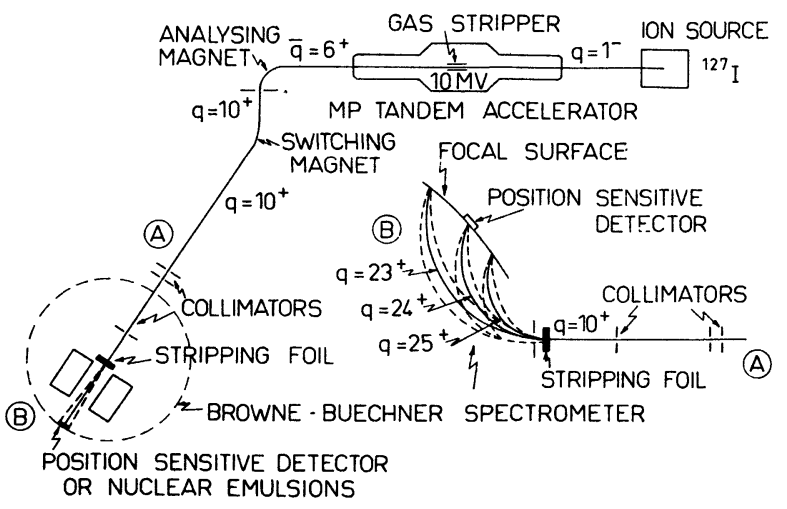

FIG. 1. - Diagram of the experimental setup.

collimators, we had a beam dispersion of $0.5 \mathrm{mrad}$. The measured energy resolution was $5 \times 10^{-4}$. Even with these small intensities we had to use in most cases the gas stripper at the MP terminal, as the lifetime of the terminal foils was too short. The main apparatus of the experiment was a Browne-Buechner spectrometer $(K=30)$. The resolving power can attain the value 1800 , but the magnet was incapable of deflecting the incident $I$ beam $\left(q=10^{+}\right)$onto the focal surface and only the transmitted beam $\left(q \approx 20^{+}\right)$could be observed. Foil thickness were determined by measuring the energy-loss of $\alpha$ particles, within an experimental error of $\pm 3 \mu \mathrm{g} / \mathrm{cm}^{2}$ and no evidence for nonuniformity of the foils was observed. After stripping, the particles having an angular and an energy dispersion, were detected by a position sensitive detector or by nuclear emulsions, on the focal surface of the spectrometer. Thus, the particles were selected not only as a function of their energy, but also of their charge state. Very weak beam intensities, of the order of $10^{-6}$ particle - $\mu \mathrm{A}$ (corresponding to a current density of $10^{9}$ to $10^{10} \mathrm{pps} / \mathrm{cm}^{2}$ ) were used. During the runs, which were sometimes longer than a few hours, no change in the behaviour of the foils was observed.

The angular dispersion method was the following. The well-known Browne-Buechner spectrometer has the property of focalising on a hyperbolic surface with the energy and charge state selection along a direction called here the $x$ axis, but there is almost no focalisation in the perpendicular direction. A position sensitive detector, $45 \mathrm{~mm}$ long, was placed on the focal surface with its position direction along the $x$ axis. By varying the field, the particle groups corresponding to the different charge states could be brought into the region covered by the detector. The resolution in position of the counter was $1 \mathrm{~mm}$. The detector was covered by a mask exposing a region of dimensions: 
$x=45 \mathrm{~mm}, y=0.5 \mathrm{~mm}$. For a given charge state, the angular distribution was measured observing the counting rate as a function of the angle between the beam and the spectrometer direction.

In another method also used, the position sensitive detector was turned perpendicular to that just described, where now the position measurement is directly related to the scattering angle. We have verified that the two methods give consistent results.

Using the same equipment, we have measured the energy straggling. The position sensitive detector was placed along the focal surface of the spectrometer. The peaks corresponding to the different charge state were observed by varying the field. The value of the straggling $\delta E$ was determined from the full width at half maximum of these peaks (FWHM), taking into account corrections due to the energy fluctuation of the incident beam and the intrinsic resolution of the apparatus.

Instead of a position sensitive detector, nuclear emulsions were also used. In this way the whole spectrum of charge states could be obtained in a single exposure. This method is more reliable for certain aspects, though, on the other hand, the results are obtained after a long and tedious scanning.

From the energy calibration of the spectrometer the total energy loss $\Delta E$ in the targets was obtained simultaneously. Combining these $\Delta E$ values with the thickness measurements, we found an agreement within $5 \%$ for the $\mathrm{d} E / \mathrm{d} x$ values tabulated by Northcliffe and Schilling [6,7].

For the charge state measurements which are related to the equilibrium thickness studies we used the same instrumentation with the foil in the object position of the spectrometer. The counting rate variations in the detector, versus the magnetic field was done automatically using a multiscaling technique which made these measurements fast and easy.

For life-time measurements we had to use the largest current density available from the MP i.e. several $\mu \mathrm{Ap} / \mathrm{cm}^{2}$ for $\mathrm{Ni}$ and $\mathrm{I}$ on an area of $1.5 \mathrm{~mm}^{2}$, consistent with the Ganil project. But of course these densities will occur on $100 \mathrm{~mm}^{2}$ area in the Ganil machine. In the case of $\mathrm{Au}$, the intensity was 20 times less. For these experiments the exposed foil was not in the spectrometer but several meters upstream, in $\mathrm{C}_{1}$ (Fig. 2), inside a target box with a vacuum of several $10^{-6}$ torr. We added a cold finger and so the vacuum

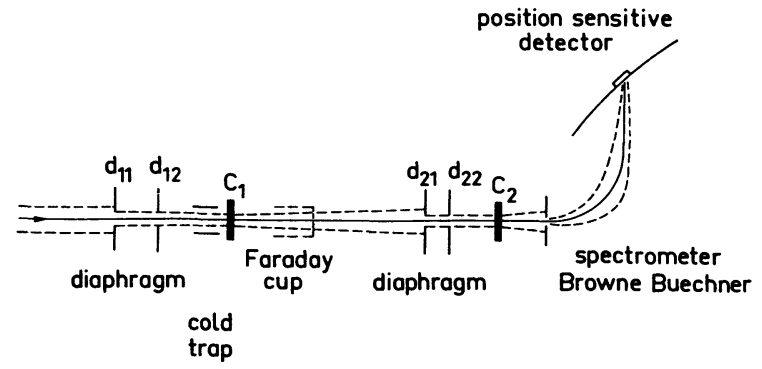

FIG. 2. - Experimental setup for the lifetime measurements. could be lowered to some $10^{-7}$ torr. The beam ions going through the target $C_{1}$ showed a change in charge state and undergo an increase of angular and energy dispersion. This stripped beam, after again collimation, hits a second foil $\mathrm{C}_{2}\left(8-10 \mu \mathrm{g} / \mathrm{cm}^{2}\right)$ positioned in the spectrometer object position. This second target represents a well defined object. As there is no change in the beam energy between $C_{1}$ and $\mathrm{C}_{2}$ the charge spectrum does not change at the second stripper. The diaphragms $d_{21}$ and $d_{22}$ extract from the angular enlarged beam a quasi-parallel part on $\mathrm{C}_{2}$, where a new angular straggling takes place. The intensity on $C_{2}$ is 100000 times smaller that on $\mathrm{C}_{1}$ and so $\mathrm{C}_{2}$ does not undergo any alteration. The detector placed on the focal surface enables the energy straggling $\delta E$ to be measured. These values are composed of the incoming beam energy dispersion, due to the two foils $C_{1}$ and $C_{2}$ and by several less important instrumental effects. Therefore we could determine $\delta E$ corresponding only to $\mathrm{C}_{1}$. If we compare the measurement with and without $\mathrm{C}_{1}$ in place, we can also determine, with great precision, the energy loss in the foil and its thickness. This method was compared with the $\alpha$ particle energy loss method indicated earlier. With this experimental layout we could measure during the time of bombardment, the intensity of the incident beam, the energy loss in a foil, its thickness variation, the energy straggling and its variation in time. The angular straggling could not be observed, but the variation of intensity after straggling gave an indication of the importance of this phenomenon.

2. Experimental results. - 2. 1. Angular STRAGGLING (1). - Theoretical calculations has been given in several papers, by L. Meyer [9], Sigmund and Winterbon [10] and others. In these theories only atomic collisions are taken into account, because electronic excitations give only a small contribution to the angular straggling. Generally, the experimental results obtained elsewhere $[11,24]$ are considered to be in very satisfactory agreement with these predictions. However these experiments were performed in lower energy regions, and moreover, using lighter ions. It should be noted that neither in the theory given by Meyer, nor in the experiments quoted above, was any distinction made between the different charge states after stripping.

The following conclusions have been found in the present work (Fig. 3). The right order of magnitude for the values predicted by the calculations of Meyer has been obtained within some limitations however. Firstly the angular dispersion increases with the charge state after stripping. This phenomenon is shown in figures 4 and 5 , where an increase of 15 to 30 per cent for the $\theta_{1 / 2}$ values is observed between the

(1) These results have been reported in greater detail elsewhere [8]. 


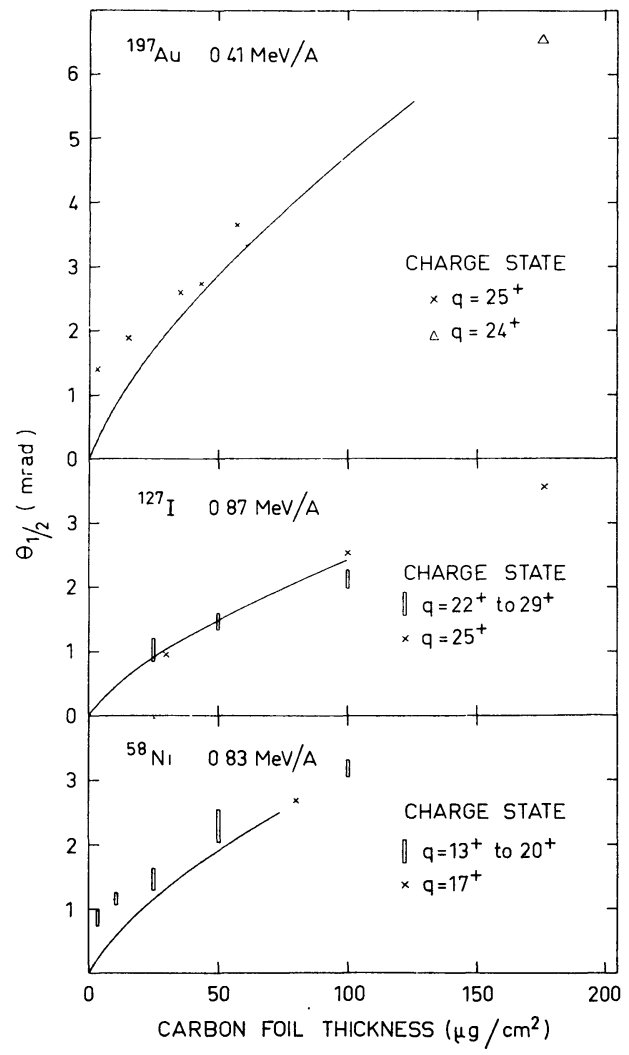

FIG. 3. - Values of the angular dispersion $\theta_{1 / 2}$ (HWHM) as a function of the foil thickness. The $\theta_{1 / 2}$ values have been corrected for the incident beam width and the spectrometer aberrations. Uncertaintities on the $\theta_{1 / 2}$ values are less than $10 \%$.

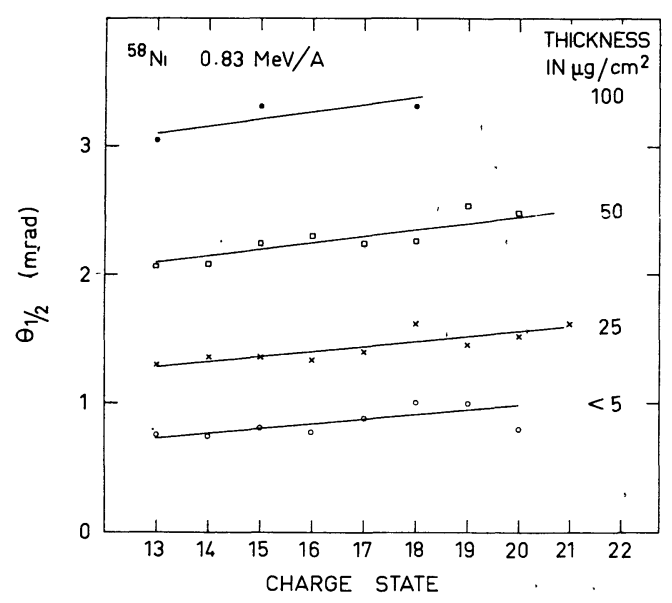

Fig. 4. - Values of the angular dispersion $\theta_{1 / 2}$ (HWHM) versus the charge state for different foil thicknesses.

lowest and the highest charge state analysed. Secondly, the agreement is better for foils thicker than the equilibrium thickness. For thinner foils, even though the uncertainties introduced by the corrections for beam width and spectrometer aberrations increase, it appears that the scattering angle becomes much larger than predicted. For the thinest foils the theoretical predictions do not hold at all. E. Efken et al. [22] observed a similar result in their angular straggling experiments with gas stripper.

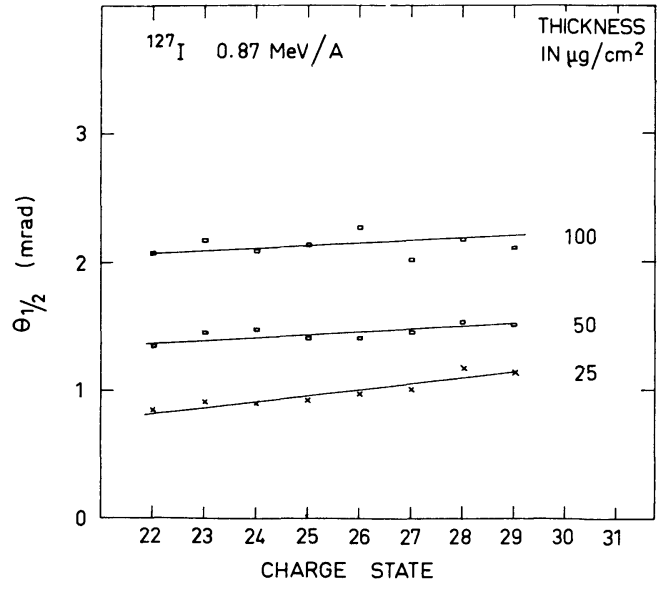

FIG. 5. - Values of the angular dispersion $\theta_{1 / 2}$ (HWHM) versus the charge state for different foil thicknesses.

2. 2. Energy StRaGgling. - The energy loss and the energy straggling are due, at the energies considered here, mainly to the electronic excitation of the atom. N. Bohr [25] [26] has studied this for many years and recently Vaviloy [27], Tschalär [28, 29] and Clarke [30] in particular calculated this phenomenon for thin foils. All this authors used only collision cross sections, but more recently O. Vollmer [31] V. V. Avdeichikov [32] and B. Efken [33] used charge changing cross sections leading to larger values of $\delta E$.

Our results are shown in figures 6 and 7 along with the theoretical predictions of Clarke. We see a large discrepancy which could be explained by the charge exchange cross section.

These divergences can also be due to foil thickness inhomogeneities. Indeed variations of $\pm 1 \mu \mathrm{g} / \mathrm{cm}^{2}$ lead to an apparent dispersion of $60 \mathrm{KeV}$ in the case of $I$. As pointed out before, we think that these inhomogeneities are small. The experimental values in figure 7 are corrected for a natural width that we observed with a $2 \mu \mathrm{g} / \mathrm{cm}^{2}$ foil. This width include instrumental effects, beam width and possible inhomogeneities. We observed also that we could reproduce our results displacing the position of the foil. (see also [34]).

2. 3. LIFETIME AND BEHAVIOUR OF FOILS DURING BOMBARDMENT. - For this experiment we used a large beam, typically around $50 \mathrm{nAp}$ and a beam density of several $\mu \mathrm{Ap} / \mathrm{cm}^{2}$.

The bombarded foils are destroyed by irradiation damage and also by sputtering and heating effects. The irradiation damage is related to the number of displaced atoms, which is proportionnal to $Z^{2} / E / A$, the current density $I / S$ and the time. Measurements have been done in a normal vacuum (several $10^{-6}$ torr) and also in a good vacuum $\left(\approx 10^{-7}\right.$ torr $)$.

Table II give results of 24 exposures, using foilthicknesses between 20 and $50 \mu \mathrm{g} / \mathrm{cm}^{2}$ and times between 1 and 6 hours.

The results of our experiments are classified as follows: the thickening phenomenon in normal 


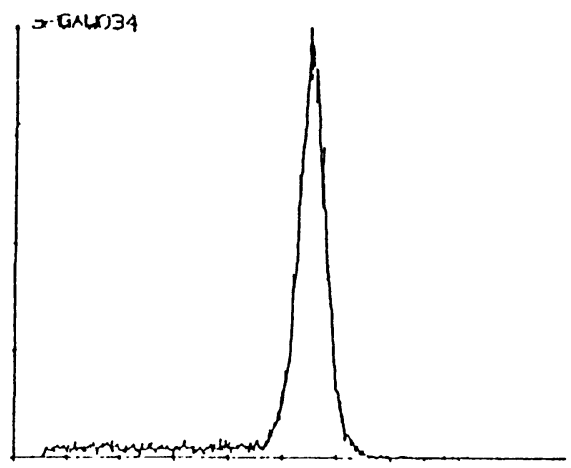

Au $0.41 \mathrm{MeV} / \mathrm{A}$
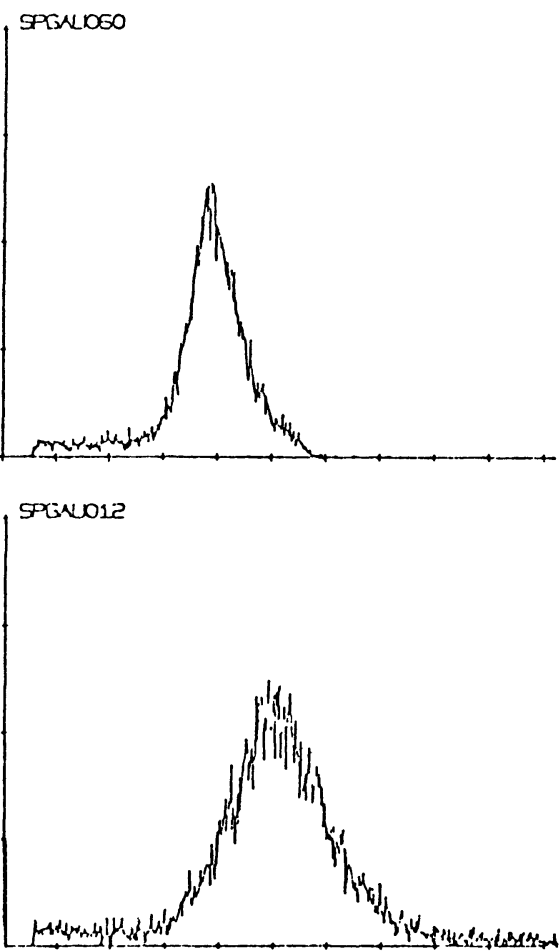

$$
80 \mu \mathrm{g} / \mathrm{cm}^{2}
$$$$
100 \mu \mathrm{g} / \mathrm{cm}^{2}
$$

Fig. 6. - Measurement of the energy straggling. Spectra observed from the position sensitive detector. $\delta E$ has been calculated from width of this spectra.

vacuum and in good vacuum, the evolution of the energy straggling and the photographic observations.

During bombardment with $\mathrm{Ni}$ and $\mathrm{I}$ in the normal vacuum we observed a thickening proportional to the time as well as to the incoming charge (number of particles) and also to the energy dissipation in the foil. If we try to make a synthesis of the results we calculate a thickening rate of $0.30 \pm 0.20 \mu \mathrm{g} / \mathrm{cm}^{2} / \mathrm{mC} / \mathrm{cm}^{2}$ corresponding to $2.1 \pm 0.2 \mu \mathrm{g} / \mathrm{cm}^{2} /$ hour. Even with the very small $\mathrm{Au}$ beam, we observed a considerable thickening rate $(\approx 49)$ if we expressed it versus $\mathrm{mC} / \mathrm{cm}^{2}$ but this corresponds to only $2 \mu \mathrm{g} / \mathrm{cm}^{2} /$ hour. We observed also a saturation.

This thickening seems to be a very well known phenomenon rising from hydrocarbon cracking in the residual vacuum. By cooling, which brings the vacuum down by a factor 10 , we can hope that this carbon deposit will disappear.

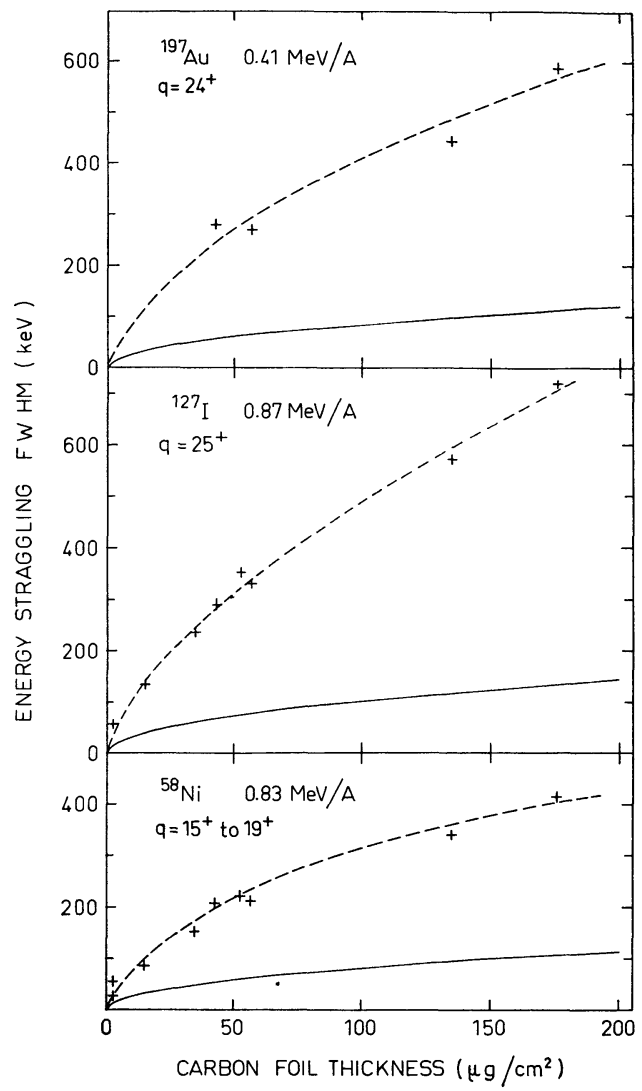

FIG. 7. - Experimental values of the energy straggling $\delta E$ (FWHM). The dashed curve is a guide to the eye whereas the solid line correspond to the theoretical predictions of Clarke.

In fact this is observed, in the case of the $\mathrm{Ni}$ beam: there is no longer a thickening and even a diminution in thickness probably due to sputtering.

But it is different for $\mathrm{I}$, where we continue to observe a thickening rate of $0.17 \pm 0.08$ $\mu \mathrm{g} / \mathrm{cm}^{2} / \mathrm{mC} / \mathrm{cm}^{2}$ or $2.3 \pm 1.7 \mu \mathrm{g} / \mathrm{cm}^{2} /$ hour. This growth is smaller but still important, if we consider that the deposit due to the cracking is low, as is suggested by the $\mathrm{Ni}$ experiment. This can perhaps be explained by a migration connected with a structure change in the carbon:

Several other groups reported similar conclusions: see Whitmell et al. [35, 36] and Yntema [37] for instance. This last author proposed heating the foils to increase the life. In our case we calculated that during the bombardment the temperature was between $600^{\circ} \mathrm{C}$ and $800^{\circ} \mathrm{C}$ (for $\mathrm{I}$ and $\mathrm{Ni}$ ) and consequently we did not heat the foils from an external source (see also [38]).

In the case of $\mathrm{Au}$ beam we saw a large thickening even with the good vacuum but after one hour there was a saturation and a much smaller growth rate.

But in fact this thickening is not related directly to a lifetime, if we can adjust the accelerator in such a way to compensate the supplementary energy loss.

Another important parameter related to the life of the foil is the energy straggling. It indicates the apparition of inhomogeneities and could be a criterion of the 


\section{TABLE II}

2) Thickness $\Delta x$ in $\mu \mathrm{g} / \mathrm{cm}^{2}$, * means 2 month old foils, otherwise we used new foils.

3) Vacuum, C means normal vacuum $\approx 10^{-6}$.

9) The impact area was determined from the photographies.

13) $\Delta e \mu \mathrm{g} / \mathrm{cm}^{2}$, thickening of the foil during exposure.

14) Thickening rate expressed versus the number of incident particles.

15) Thickening rate expressed versus the bombardment time.

16) This product is characteristic of the inverse of the lifetime.

18) + means that the foils was destroyed at the end of the experience.

\begin{tabular}{|c|c|c|c|c|c|c|c|c|}
\hline 1 & 2 & 3 & 4 & 5 & 6 & 7 & 8 & 9 \\
\hline No & $\underset{\mu \mathrm{g} / \mathrm{cm}^{2}}{\Delta x}$ & $\begin{array}{c}\text { Vacuum } \\
\times 10^{-7} \\
\end{array}$ & Ion & ${ }^{E} \mathrm{MeV}$ & $\begin{array}{c}E / A \\
\underline{\mathrm{MeV} / A}\end{array}$ & $\begin{array}{c}q \\
\text { Charge } \\
\text { state } \\
-\end{array}$ & $\stackrel{I}{\mu \text { Ap }}$ & $\begin{array}{c}S \\
\mathrm{~cm}^{2} \\
-\end{array}$ \\
\hline $\begin{array}{r}1 \\
2 \\
3 \\
4 \\
5 \\
6 \\
7 \\
8 \\
9 \\
10 \\
11\end{array}$ & $\begin{array}{l}18 \\
20 \\
18 \\
18 \\
18 \\
19 \\
30^{*} \\
32 * \\
42^{*} \\
18^{*} \\
41^{*}\end{array}$ & $\begin{array}{c}20 \mathrm{C} \\
20 \mathrm{C} \\
20 \mathrm{C} \\
4 \\
4 \\
4 \\
70 \mathrm{C} \\
60 \mathrm{C} \\
5 \\
4 \\
4\end{array}$ & $\begin{array}{l}\text { I } \\
\text { ” } \\
” \\
” \\
" \\
" \\
"\end{array}$ & 110 & 0.87 & 10 & $\begin{array}{l}0.009 \\
0.039 \\
0.021 \\
0.025 \\
0.040 \\
0.040 \\
0.070 \\
0.070 \\
0.080 \\
0.085 \\
0.085\end{array}$ & $\begin{array}{c}0.015 \\
\# \\
\# \\
" \\
0.013 \\
\# \\
" \\
"\end{array}$ \\
\hline $\begin{array}{l}12 \\
13 \\
14\end{array}$ & $\begin{array}{l}17 \\
20 \\
50\end{array}$ & $\begin{array}{c}20 \mathrm{C} \\
8 \\
2\end{array}$ & $\begin{array}{c}\mathrm{Au} \\
\dddot{\eta}\end{array}$ & 80 & 0.4 & 10 & $\begin{array}{l}0.00015 \\
0.00015 \\
0.00015\end{array}$ & $\begin{array}{c}0.015 \\
"\end{array}$ \\
\hline $\begin{array}{l}15 \\
16 \\
17 \\
18 \\
19\end{array}$ & $\begin{array}{l}20 \\
20 \\
13 \\
14 \\
65\end{array}$ & $\begin{array}{c}5 \\
2 \\
40 \mathrm{C} \\
6 \\
6\end{array}$ & $\begin{array}{c}\text { Ni } \\
" \\
" \\
"\end{array}$ & 48 & 0.8 & 5 & $\begin{array}{l}0.080 \\
0.080 \\
0.050 \\
0.03 \\
0.05\end{array}$ & $\begin{array}{c}0.02 \\
" \\
" \\
"\end{array}$ \\
\hline $\begin{array}{l}20 \\
21 \\
22 \\
23 \\
24\end{array}$ & $\begin{array}{l}20 \\
50 \\
20 \\
20^{*} \\
50^{*}\end{array}$ & $\begin{array}{c}30 \mathrm{C} \\
30 \mathrm{C} \\
3 \\
3 \\
3\end{array}$ & I & 110 & 0.87 & 10 & $\begin{array}{l}0.045 \\
0.045 \\
0.045 \\
0.045 \\
0.045\end{array}$ & $\begin{array}{c}0.015 \\
” \\
” \\
”\end{array}$ \\
\hline
\end{tabular}

end of the foil. We can say that deterioration rate of this quantity gives a number related to the lifetime, because the alteration of the energy dispersion of the beam leads to a diminution of intensity after passing the second stage of acceleration and beam transport system.

The conclusion of all our measurements is that the energy straggling varies slowly and this variation is only connected with the thickness variation of the foil. This allows us to say that carbon deposit, migration, and sputtering are homogeneous. Variations of $1 \mu \mathrm{g} / \mathrm{cm}^{2}$ could be easily observed. But in several cases after a long bombardment, we had an exception. After a few hours of bombardment, suddenly in less than 15 minutes, the $\delta E$ blows up by a factor of 5 or more. This indicates desintegration of the foil prelude to its destruction. Efken [33] made a similar observation.

In other cases, with I beam, the foils break; this is another way to determine the lifetime of the foil. In the case of $\mathrm{Ni}$ we could not destroy the foil even after 4 hours bombardment whereas for I the lifetime was between 3-5 hours. See also $\left({ }^{2}\right)$ [39, 40].

Most of the foils have been photographied (Figs. 8, $9,10)$ and this report shows several of this pictures. We cannot see a difference for a good or normal

${ }^{2}{ }^{2}$ F. Selph, Berkeley, private communication.

$$
\begin{aligned}
& 11 \\
& \begin{array}{l}
\text { Time } t \\
\text { hour }
\end{array} \\
& - \\
& 4 \\
& 1.42 \\
& 3.13 \\
& 4.5 \\
& 2.5 \\
& 5.75 \\
& 1.75 \\
& 3.3 \\
& 2 \\
& 2 \\
& 1 \\
& 3.42 \\
& 4 \\
& 3.25 \\
& 1.5 \\
& 3.7 \\
& 3 \\
& 4 \\
& 3.3 \\
& 3 \\
& 2.2 \\
& 3 \\
& 2 \\
& 2
\end{aligned}
$$

12
$\begin{gathered}J t \\ \mu \mathrm{Cp} /\end{gathered}$
$\mathrm{cm}^{2}$
-
8600
13200
16000
24000
24000
55000
34000
64000
44000
47000
23000
123
144
117
20000
52000
27000
21000
30000
32000
23000
32000
22000
22000

\begin{tabular}{cc}
14 & 15 \\
$\frac{\tau=\Delta e}{J t}$ & \\
\hline$J t$ & $\tau^{\prime}=$ \\
$\times 10^{-3}$ & $\Delta e / t$ \\
- & - \\
0.8 & 1.75 \\
0.25 & 2.2 \\
0.32 & 1.85 \\
0.18 & 1.14 \\
0.10 & 1.32 \\
0.17 & 1.65 \\
0.11 & 2.13 \\
0.26 & 5.1 \\
0.26 & 5.85 \\
0.17 & 4.15 \\
0.36 & 8.9 \\
$49 / 12$ & $2 / 0.3$ \\
$10 / 0$ & $0.5 / 0$ \\
$36 / 0$ & $1.5 / 0$ \\
& - \\
$\bar{Z}$ & - \\
0.27 & 2.4 \\
$=$ & - \\
\hline & - \\
0.18 & 1.9 \\
0.20 & 2.2 \\
0.11 & 1.17 \\
0.09 & 1.5 \\
0.13 & 1.5
\end{tabular}

vacuum but we see in all cases a blackening at the beam impact. Usually at this impact the foil is stret-

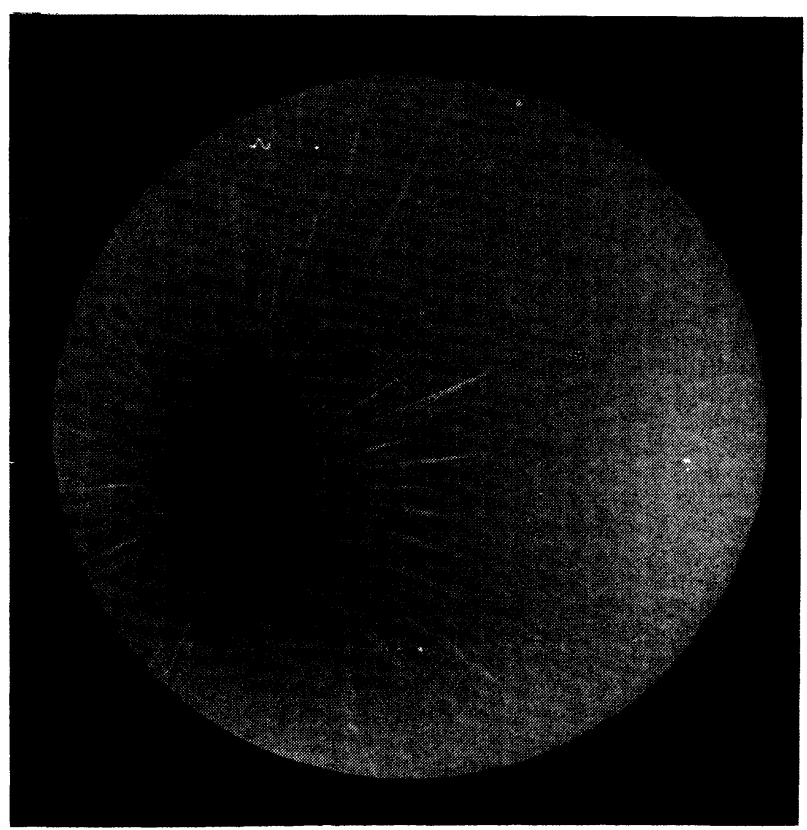

FIG. 8. - Photography of the foil corresponding to the experiment number 16 of table II. The diameter of all foils shown here is $6 \mathrm{~mm}$ and the beam impact area was between 1.3 and $2 \mathrm{~mm}^{2}$. The experimental conditions were: $20 \mu \mathrm{g} / \mathrm{cm}^{2}$, Ni $5^{+} 48 \mathrm{MeV}$ $0.8 \mathrm{MeV} / A, 4 \mu \mathrm{Ap} / \mathrm{mm}^{2}$, exposure time 3.7 hours, vacuum $2-$ $6 \times 10^{-7}$ torr. We do not observe a foil thickening but we see a blackening of the impact and radial folds. 




FIG. 9. - Photography of the foil number 2 of table II $20 \mu \mathrm{g} / \mathrm{cm}^{2}$, I $10^{+} 110 \mathrm{MeV} 0.87 \mathrm{MeV} / A, 2.6 \mu \mathrm{Ap} / \mathrm{mm}^{2}$, exposure time 1.4 hours, $20 \times 10^{-7}$ torr. In this case we observed a foil thickening. The general aspect is similar as in the case of figure 8 . The region on the right of the main impact is due to a short $(1 \mathrm{~min}$.) exposure to the beam. The blackening appears immediately but not the folds.

ched and we see radial folds corresponding to the tightening. Older foils (2 months) shows a different picture than new foils, a larger number of foldsis in the first case. The lifetime is not different but with older foils we observed the phenomenon of the energy straggling blow up. We see on other pictures that the very tiny $\mathrm{Au}$ beam does not produce folds but a deformation of the impact area.

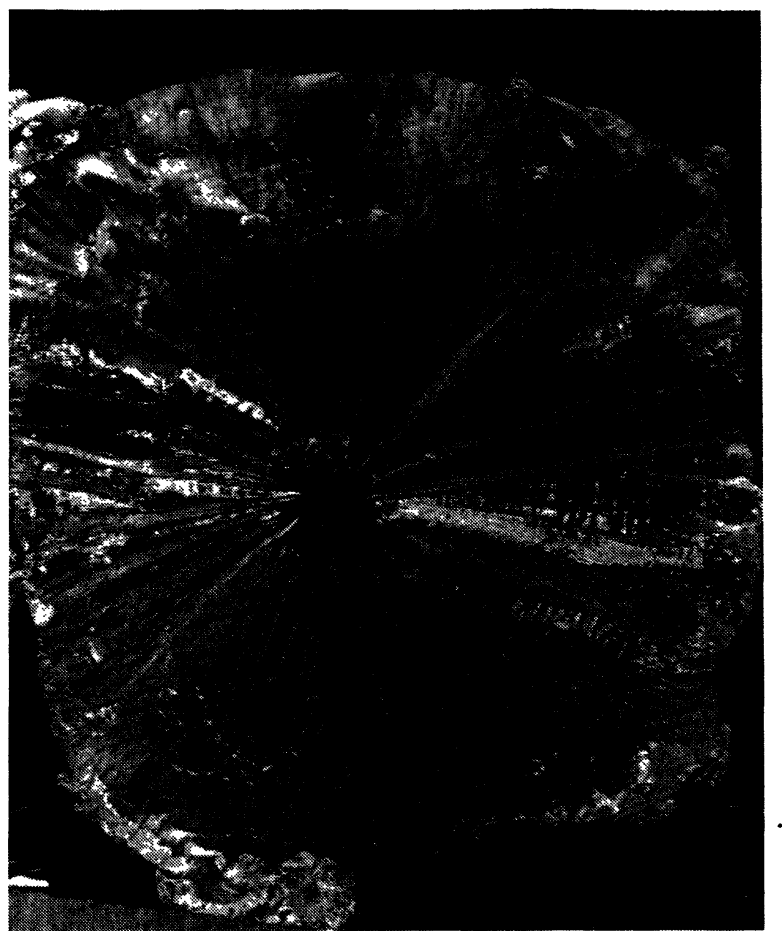

Fig. 10. - Photography of a two months old foil whereas figure 8 and figure 9 correspond to new foils. Experiment number 11 of Table II: $41 \mu \mathrm{g} / \mathrm{cm}^{2}, \mathrm{I}^{+}+64 \mathrm{MeV} 0.5 \mathrm{MeV} / A, 6.5 \mu \mathrm{Ap} / \mathrm{cm}^{2}$, exposure time 1 hour, $4 \times 10^{-7}$ torr. The observed picture is completely different. We see many small folds over the whole non bombarded area. In the case of the use of old foils we observed the energy straggling blow up.

Before we close this point of our study, we whish to report information from the G.S.I. Darmstadt (3),

(3) B. Franzke, private communication.

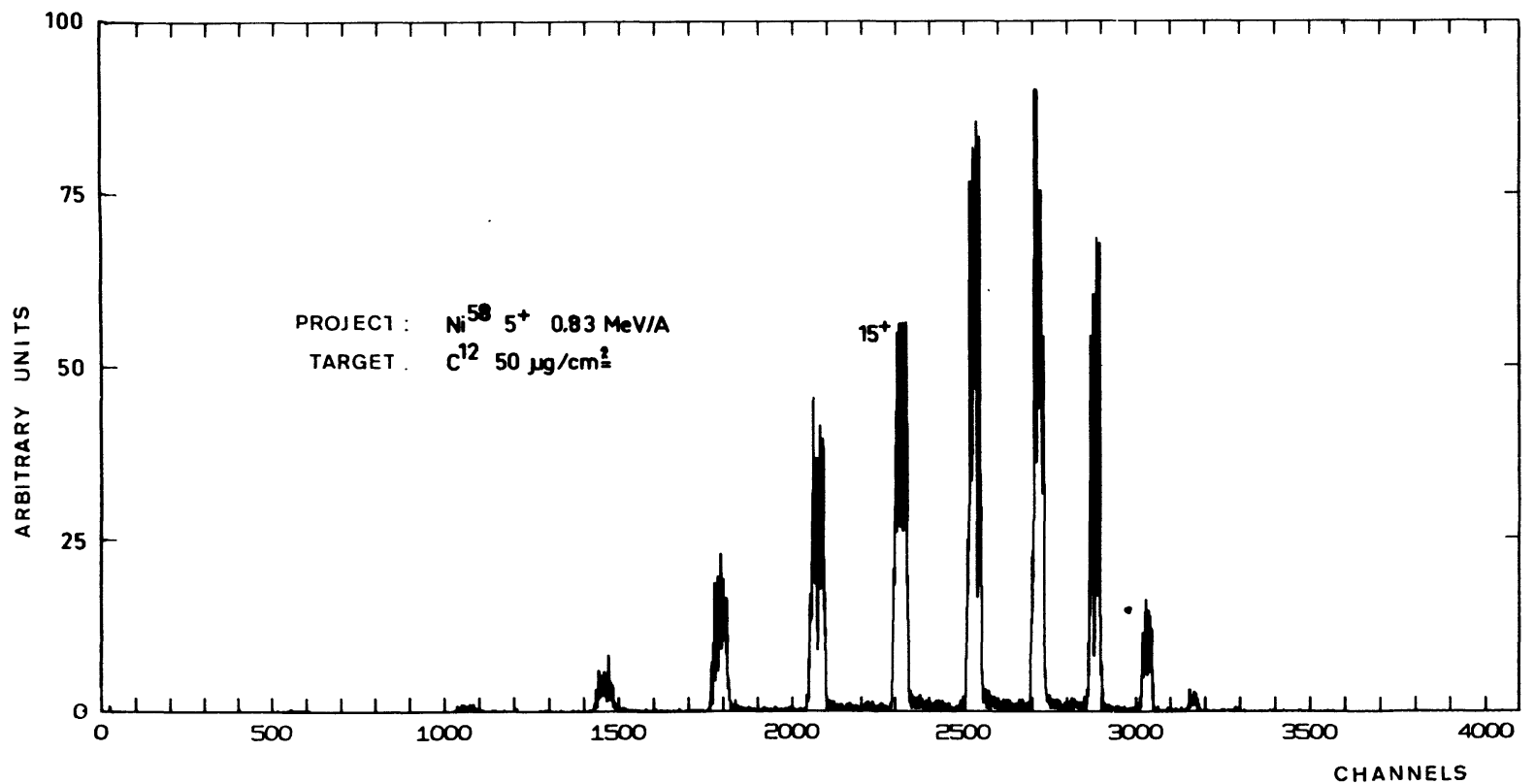

Fig. 11. - Charge state spectra in the case where the incident ions were $\mathrm{Ni}^{+}$at $0.83 \mathrm{MeV} / A$. 
according to which, foils were used in similar conditions as for Ganil (Xe beam, several $\mathrm{p} \mu \mathrm{A}$ on $1 \mathrm{~cm}^{2}$ ). In their case it seems that the foils diminished in thickness, which means that sputtering is more important than carbon deposit or migration.

2. 4. Charge State SPECTRA. - Figures 11 and 12 show the result of measurements of charge state spectra. We have results for $\mathrm{I}, \mathrm{Ni}$ and $\mathrm{Au}$ beams at several energies. We notice in figure 12 , showing the

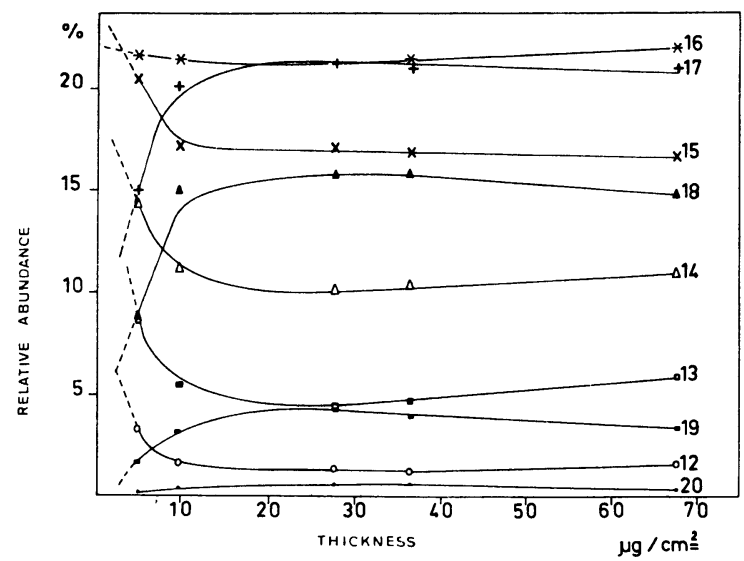

Fig. 12. - Variation of the yield for the different charge states versus the foil thickness for $\mathrm{Ni} 5^{+} 0.83 \mathrm{MeV} / A$ incident ions.

variation of relative intensities versus the thickness of the foils, that the curve corresponding to the mean charge is roughly constant whereas neighbouring charge states vary greatly. This leads us to reexamine the application of the equilibrium thickness parameter. One see that for the mean charge $q$, even a thickness much smaller than for equilibrium, gives always a high yield. Under these conditions we will have less straggling.

We see also that for a large thickness the yield is not constant. This is due to the angular straggling and the limited acceptance of the spectrometer. $90 \%$ of the equilibrium yield is obtained for a thickness of $15 \mu \mathrm{g} / \mathrm{cm}^{2}$ for Ni at $0.85 \mathrm{MeV} / A$ and of $25 \mu \mathrm{g} / \mathrm{cm}^{2}$ at $1.53 \mathrm{MeV} / A$, for I we found $15 \mu \mathrm{g} / \mathrm{cm}^{2}$ at $0.87 \mathrm{MeV} / A$ and for $\mathrm{Au} 15 \mu \mathrm{g} / \mathrm{cm}^{2}$ at $0.5 \mathrm{MeV} / A$.

3. Conclusion. - The angular straggling experiments showed that the theoretical predictions of L. Meyer can be used as a guide for calculation. For charge states far from the mean charge the angular straggling is larger up to $40 \%$ for a $15 \mu \mathrm{g} / \mathrm{cm}^{2}$ foil for example. For thinner foils the angular straggling goes to a finite value and not to zero.

Concerning the energy straggling, our experimental values are 3-4 times larger in comparison with the theoretical predictions of $\mathrm{P}$. Vavilov, C. Tschalär, N. M. Clarke.

If the foils are bombarded with large intensities according to the Ganil values (several $\mu \mathrm{Ap} / \mathrm{cm}^{2}$ ) we observe in a normal vacuum a thickening due to the hydrocarbon cracking. In a good vacuum $\left(10^{-7}\right)$ the thickening disappears for $\mathrm{Ni}$, but persists in the case of $\mathrm{I}$ or $\mathrm{Au}$.

The energy straggling varies slowly during bombardment. The destruction of a foil can be due to a breakage but also in some case through the appearance of a energy straggling blow up.

As a last and somewhat speculative conclusion we can try to extrapolate the lifetime from the observed values. For this we suppose that it is proportional to the number of atoms displaced and we suppose also that we can extrapolate from a small area $\left(2 \mathrm{~mm}^{2}\right)$ to $1 \mathrm{~cm}^{2}$ which may be the beam size in the case of Ganil.

With all this restriction, the lifetime of the foil may be 3-17 hours for I, much less for $\mathrm{Au}$ (2-5 hours) and much more (14-120 hours) for Ni. This numbers correspond to the lower and higher energy limit of the Ganil project.

Acknowledgements. - We thank Dr. B. Franzke from the G.S.I. in Darmstadt for many valuable discussions on the stripping foil experiments.

\section{References}

[1] Rapport du Groupe de travail pour l'accélérateur national à ions lourds (IN2P3 - CEA) juillet 1973

[2] Avant-projet de l'accélérateur national à ions lourds (IN2P3 CEA) avril 1975

[3] LeISCHNeR E., Rapport UNILAC 1-66 (1966) Heidelberg, BeTZ H. D. and SChmelzer CH., Rapport UNILAC 1-67 (1967) Heidelberg.

[4] Betz H. D., Rev. Mod. Phys. 44 (1972) 465.

[5] Baron E., thesis Université de Paris-Sud (1975)

[6] NorthCliffe L. C., Annu. Rev. Nucl. Sci. 13 (1963) 67.

[7] Northcliffe L. C. and Schiluing R. F., Nucl. Data A7 (1970) 233

[8] Frick G., Gehringer C., Heusch B., Ricaud Ch., WAGNer P., Baron E., IEEE NS 23-2 (1975) 1137.

[9] Meyer L., Phys. Status Solidi 44b (1971) 253.

[10] Sigmund P. and Winterbon K. B., Nucl. Instrum. Methods 119 (1974) 541

[11] Hooton B. W., Freeman J. W. and Kane P. P., Nucl. Instrum. Methods 124 (1975) 29.
[12] Ormrod J. H. and Duckworth H. E., Can J. Phys. 41 (1963) 1424

[13] Hógberg G., Nordin N. and Berry H. G., Nucl. Instrum. Methods 90 (1970) 283.

[14] Anderson T., Jessen K. and Sorensen G., Nucl. Instrum. Methods 90 (1970) 41 .

[15] Bernhard F., Lippold F., Meyer L., Schwabe S. and Stolle R., Proc. of the International Conference on Atomic Collision Phenomena. (Brighton, Ed. North-Holland Pub. Co.) 1970663.

[16] Schwabe J. and Stolle R., Phys. Status Solidi 47b (1971) 171

[17] Andersen H. and Boettiger J., Phys. Rev. B1 (1971) 2105 and IEEE Trans. Nucl. Sci. NS-19 2 (1972) 274.

[18] Bednyakov A. A. et al. Sov. Phys. JETP 23 (1966) 391.

[19] Sakisaka M., Yamazaki T. and TaKasaki M., J. Phys. Soc. Japan 29 (1970) 1551.

[20] Cline C. K., Pierce T. E., Purser K. H. and Blann M., Phys. Rev. 180 (1969) 450. 
[21] Spahn G. and Groeneveld K. O., Nucl. Instrum. Methods 123 (1975) 425.

[22] EfKen B., Hahn D., Hilscher D. and Wüstefeld G., Nucl. Instrum. Methods 129 (1975) 219.

[23] Andersen H. H., Bøttiger J., Knudsen H., Phys. Rev. A7 (1973) 154

[24] Armitage B. H., Trehan P. N., Nucl. Instrum. Methods. 134 (1976) 359.

[25] Bohr N., K. Dansk. Viden. Selsk. Mat. Fys. 18 (1948) 8.

[26] Evans R. D., The Atomic Nucleus, (Ed. McGraw-Hill Book Co) 1955.

[27] Vavilov P. V., Sov. Phys. JETP 5 (1957) 749.

[28] TSCHalär C., Nucl. Instrum. Methods 61 (1968) 141.

[29] TsChalär C., Nucl. Instrum. Methods 64 (1968) 237.

|30] Clarke N. M., Nucl. Instrum. Methods 96 (1971) 497.

|31] Vollmer O., Nucl. Instrum. Methods 121 (1974) 373.

132] Avdeichikov V. V., Ganza E. A. and Loshkin O. V., Nucl. Instrum. Methods 118 (1974) 247.
[33] EfKen B., Hahn D. Hilscher D. and Wüstefeld G., Nucl. Instrum. Methods. 129 (1975) 227.

[34] A.E.R.E. Harwell, PR/NP 23, p. 72 and also Freeman J. M., Sofield C. J., Cowern N.E.B., Mason J., Rev. Phys. Appl. 12 (1977).

[35] Whitmell D. S., Armitage B. H., Porter D. R. and Ferguson A.T.G., Proc. International Conference on the Technology of Electrostatic Accelerators, Daresbury, 47 mai 1973, (Ed. T. W. Aitken and N.R.S. Tait).

[36] Armitage B. H., Porter D. R., Whitmell D. S., Harwell AERE PR/NP 22, p. 79.

[37] YNTEMa J. L., IEEE NS 23-2 (1975) 1133.

[38] Dumont P. D., Livington A. E., Baudinet-Robinet Y., Wehr G., Quaglia L., Phys. Scr. 13 (1976) 122.

[39] Andrews, H., MacDonald A. B., Chalk River Progress Report Physics Division, 4-5. 75.

[40] RePNOw R., et coll., Max Planck Institut für Kernphysik, Heidelberg, Annual Report 1965, p. 1. 